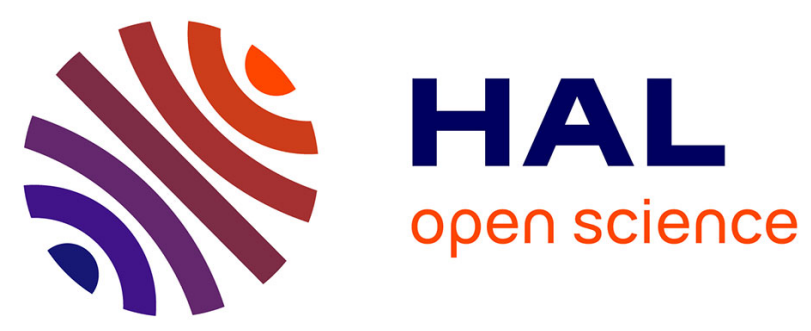

\title{
Immersed membranes configuration for the microfiltration of fruit-based suspensions
}

Camille Rouquié, Layal Dahdouh, Julien Ricci, Christelle Wisniewski, Michèle Delalonde

\section{- To cite this version:}

Camille Rouquié, Layal Dahdouh, Julien Ricci, Christelle Wisniewski, Michèle Delalonde. Immersed membranes configuration for the microfiltration of fruit-based suspensions. Separation and Purification Technology, 2019, 216, pp.25 - 33. 10.1016/j.seppur.2019.01.062 . hal-03485852

\section{HAL Id: hal-03485852 \\ https://hal.science/hal-03485852}

Submitted on 20 Dec 2021

HAL is a multi-disciplinary open access archive for the deposit and dissemination of scientific research documents, whether they are published or not. The documents may come from teaching and research institutions in France or abroad, or from public or private research centers.
L'archive ouverte pluridisciplinaire HAL, est destinée au dépôt et à la diffusion de documents scientifiques de niveau recherche, publiés ou non, émanant des établissements d'enseignement et de recherche français ou étrangers, des laboratoires publics ou privés.

\section{(c) (1) $\$$}

Distributed under a Creative Commons Attribution - NonCommercial| 4.0 International 


\section{Immersed membranes configuration for the microfiltration of fruit-based}

\section{suspensions}

Keywords: Fruit-based suspensions; Microfiltration; Immersed membranes; Productivity; Selectivity.

\section{Highlights:}

- Interest of using immersed membranes microfiltration for fruit-based suspensions

- Productivity in line with what is reported in other domains

- Selectivity goals towards compounds of interest reached

\section{Abstract}

Microfiltration is widely used to ensure the athermal stabilization, clarification and concentration of various fruit-based suspensions (e.g. fruit juices, food by-products, wine). However, the performances of membrane filtration remain highly challenged by membrane fouling. To prevent membrane fouling, cross-flow filtration is generally performed. Nevertheless, this intensive working mode is considered as highly energy consuming due to the intensive pumping required to circulate the suspension at high velocities. In the light of this, immersed membranes configurations have been developed in many fields, as they allow working in energy-friendly operating conditions. Thus, this work investigated for the first time the performances of an immersed membranes configuration for fruit-based suspensions microfiltration, in terms of productivity (membrane fouling, permeate flux) and selectivity (clarification, concentration of bioactive compounds). This study focused on three fruit-based suspensions: a grapefruit juice and two winery by-products. Concerning the process selectivity, pilot-scale experiments showed that immersed membranes filtration allowed producing retentate and permeate of quality as least as good as the one related to conventional cross-flow filtration. Concerning the process productivity, cross-flow filtration allowed reaching higher fluxes compared to immersed membranes filtration, in accordance with the conventional order of magnitude specific to each configuration. Immersed membranes configuration could find interesting applications within small production units of fruit juices and/or industries dealing with the valorization of low addedvalue byproducts thanks to its various advantages (high compactness, easy handling and mobility, low investment and operational costs). 
List of abbreviations and variables:

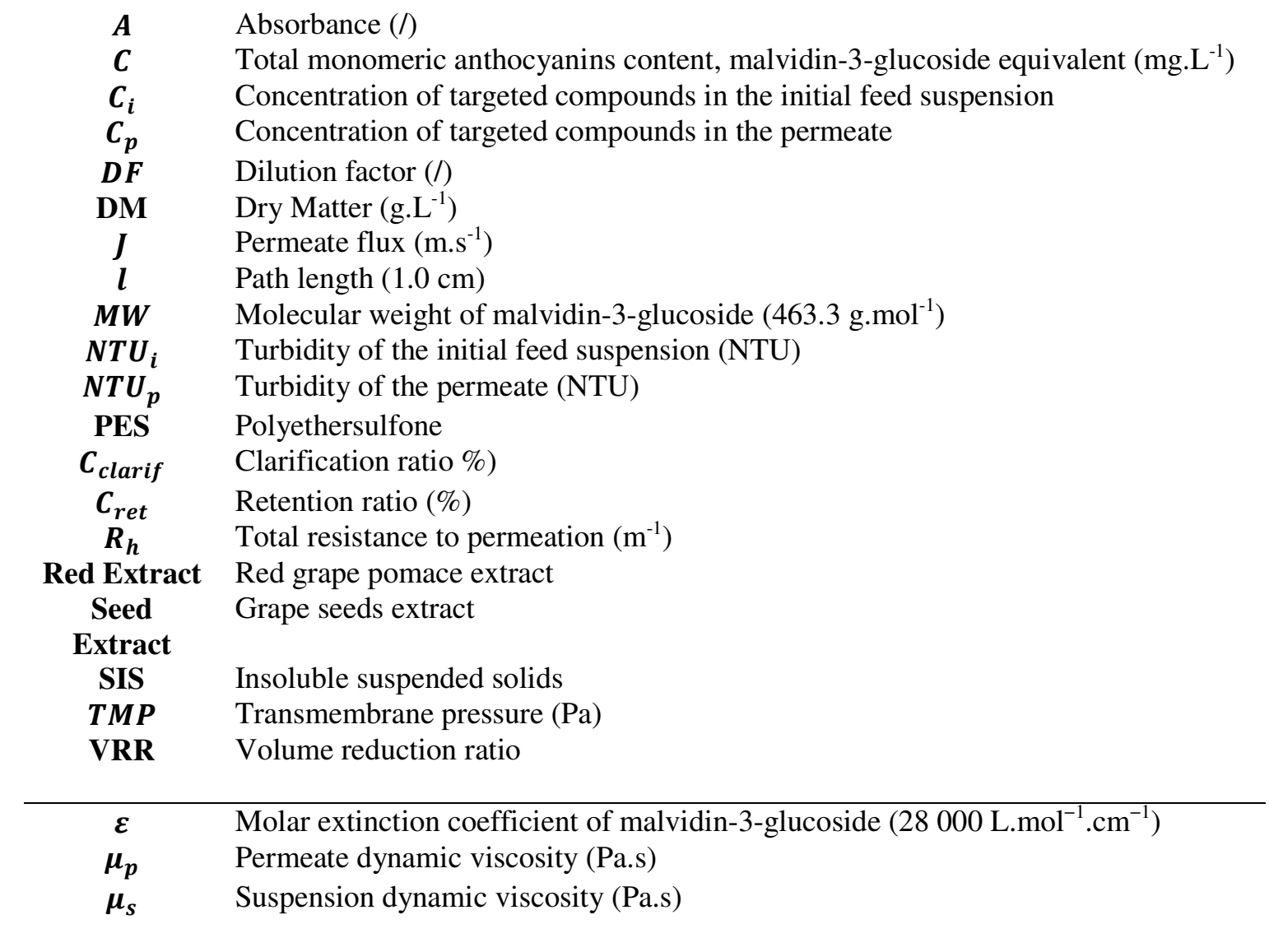

\section{5 \\ 1. Introduction}

36

37

38

39

40

41

42

43

44

45

Microfiltration is widely used to ensure the clarification and the concentration of various fruit-based suspensions such as fruit juices [1-4], agro-food by-products [5-7] or wine [8]. This solid-liquid separation technic allows producing high quality products thanks to its high selectivity and low operating temperatures. However, the performances of membrane filtration remain highly challenged by membrane fouling. Fruitbased suspensions, well known to be heterogeneous suspensions containing colloids and larger suspended insoluble solids (SIS) dispersed in a continuous aqueous phase, are considered as highly-fouling suspensions. During the microfiltration of such complex suspensions, particles deposition is considered as one of the main causes of membrane fouling $[9,10]$. This type of fouling is mainly governed by the balance between convective forces (permeate flow), leading particles to the membrane, and back-transport forces, removing particles away from the membrane surface [11]. 
So far, a wide range of filtration configurations have been studied for fruit juices microfiltration, such as cross-flow filtration using organic plane $[3,12]$ or hollow-fiber $[13,14]$ membranes, organic or inorganic tubular membranes $[2,4,15-20]$. In spite of the diversity of membrane shape and material and operating conditions, the use of high shear stress at the membrane surface is always a common feature to enhance the back-transport mechanisms and thus increase the permeate fluxes [21]. However, this intensive working mode is well known to be highly energy consuming due to the intensive pumping required to circulate the suspension at high velocities. Moreover, the use of important shear forces, leading to high turbulences, has been reported to induce particles size modifications $[22,23]$ that could impact the suspension characteristics (fouling propensity, nutritional and sensorial properties).

In the light of this, immersed membranes configuration (out-to-in filtration) could be an interesting alternative for the microfiltration of fruit-based suspensions. In this configuration, the membrane (plane or hollow fiber) is immersed in the suspension and the filtration is generally ensured by permeate suction at constant flux. Thus, the filtration operation is conducted in conditions close to that of dead-end filtration, associated with limited back-transport forces and low permeation fluxes. Despite the low permeation fluxes commonly applied in such conditions, immersed membranes filtration have been widely and successfully used in many fields, notably for water treatment (e.g. drinking water production) and for wastewater treatment for the filtration of more heterogeneous suspensions (e.g. microalgae suspensions [24-26], activated sludge [27-30]). For these applications, the relatively low productivity is generally offset by the great packing density of the membrane, by the low cost of organic membranes and the low energy consumption of the process $[31,32]$.

However, as far as the authors are aware, the performances of this filtration configuration remain little studied for fruit-based suspensions microfiltration. At present time, no studies have yet characterized the productivity and the selectivity of this filtration configuration for such applications. In the light of this, the aim of this work was to investigate the performances of an immersed membranes configuration for fruitbased suspensions microfiltration, in terms of membrane fouling and selectivity. This study focused on three different agro-food suspensions: a grapefruit juice, a grape pomace extract and a grape seeds extract. Firstly, a specific experimental strategy was conducted in order to define the optimal operating conditions of this system. Secondly, based on the previously identified operating conditions, filtration performances were analyzed in terms of membrane fouling and selectivity (clarification and/or concentration of targeted compounds). Finally, a comparison of immersed membranes configuration performances with conventional side-stream membranes configuration ones (cross-flow filtration) was proposed and discussed. 


\section{Material and methods}

\subsection{Fruit-based suspensions}

\subsubsection{Selection}

Three agro-food suspensions were studied in this work: a grapefruit juice, a red grape pomace extract and a grape seeds extract.

Grapefruit juice was chosen as it is among the most popular citrus fruits worldwide [33,34]. Moreover, its microfiltration offers several applications in fruit-juices industries as it allows producing a high quality clarified and stabilized juice rich in phenolic compounds (mainly naringin and narirutin [35]) and a concentrated pulpy fraction rich in carotenoids (mainly lycopene and beta-carotene [36]). These products find useful applications in industries (pharmaceutical, cosmetic, food) thanks to their therapeutic, nutritional and sensorial properties.

Red grape pomace and grape seeds extracts were chosen for being among the main by-products (produced by considerable tonnage) by winery industries [37]. Their valorization is a major economic and ecological challenge, for which clarification is a key pre-treatment step. The microfiltration of red grape pomace and grape seed extracts allows producing a clarified permeate rich in phenolic compounds, notably flavonoids like tannins and anthocyanins in the case of red grape pomace extract $[38,39]$. This permeate can be easily valorized through additional extraction steps.

\subsubsection{Procurement, characterization and conservation}

In this study, grapefruit juice was produced by squeezing Star Ruby grapefruit (Citrus grandis (L.) Osbeck) (Spain) in a semi-industrial extractor (Automatic orange juicer, model 32, SANTOS, Vaulx-en-Velin, France) and pre-filtered through a stainless steel sieve ( $1 \mathrm{~mm}$ mesh size). Red grape pomace extract (named Red Extract) and grape seeds extract (Seed Extract) were purchased from a local distillery located in the South of France. The extracts were obtained by industrial solid-liquid extraction in sulphited water, after grinding of the raw residues generated during winemaking (i.e. red grape pomaces and grape seeds). The three suspensions were stored at $-20^{\circ} \mathrm{C}$ and thawed before use. Their main physicochemical and chemical characteristics (dry matter (DM), turbidity (NTU), $\mathrm{pH}$, Brix degree ( ${ }^{\circ}$ Brix), dynamic viscosity $\left(\mu_{s}\right)$ and suspended insoluble solids (SIS)) were determined according to the protocols and methods described by $[37,40]$. 


\subsubsection{Experimental set-up}

110

A schematic illustration of the experimental equipment is presented in figure 1. It consisted of a $6.3 \mathrm{~L}$ stirred stainless steel feed tank, linked to a $1.8 \mathrm{~L}$ external filtration unit containing immersed organic hollow-fiber membranes (main characteristics given in table 1). A low flow-rate pump (item 3 on figure 1, 520S IP31 peristaltic pump, Watson-Marlow, Massachusetts, USA) allowed the juice flowing through the filtration unit (flow velocity of $3.5 \times 10^{-2} \mathrm{~m} . \mathrm{s}^{-1}$, corresponding to Reynolds number of around 500 in the external filtration unit with hollow-fiber membranes and to a $3 \mathrm{~s}^{-1}$ shear rate at the membrane surface). A cryostat connected to a water jacket on the recycling loop, maintained the system at a constant temperature of $25 \pm$ $2{ }^{\circ} \mathrm{C}$.

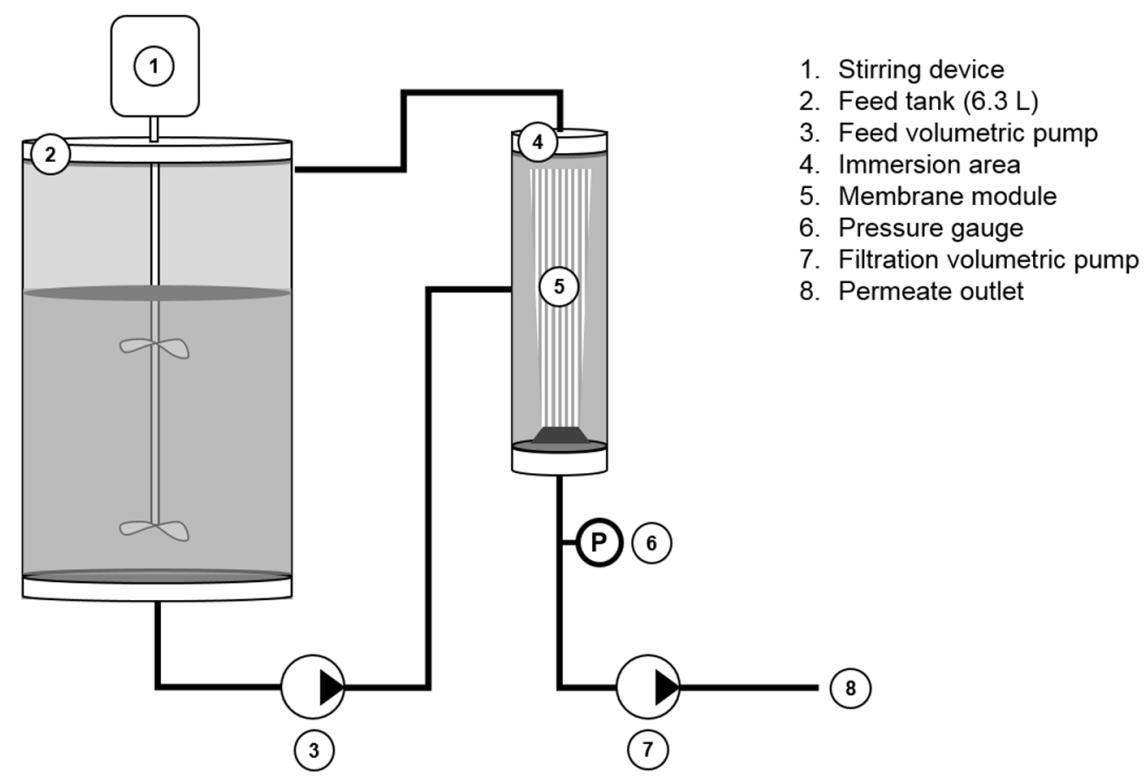




\section{Configuration Material Average pore size $(\mu \mathrm{m})$ Intrinsic membrane resistance $R_{m} *\left(\mathrm{~m}^{-1}\right)$ Water permeability * $\left(L \cdot h^{-1} \cdot m^{-2} \cdot\right.$ bar $\left.^{-1}\right)$ Manufacturer Filtration area $\left(\mathrm{m}^{2}\right)$

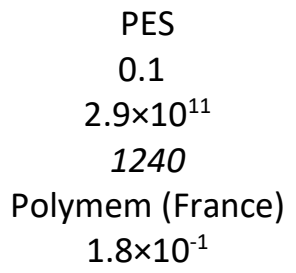

\section{* Experimental measurement at $25^{\circ} \mathrm{C}$}

The out-to-in permeation flow was ensured by pump suction (item 7 on figure 1, 621F/RE IP55 peristaltic pump, Watson-Marlow, Massachusetts, USA) at constant flux $(J)$. The evolution of membrane fouling during the filtration runs was estimated though the monitoring of the transmembrane pressure evolution (TMP) by an Almemo 2690-8 computer-controlled device (Ahlborn GmbH, Germany) connected to a pressure sensor. Indeed, according to Darcy's law (equation 1), in constant flux experiments, an increase of TMP is directly related to an increase of the resistance to permeation:

$$
J=\frac{T M P}{\mu_{p} \cdot R_{h}}
$$

With $J$ the permeate flux $\left(\mathrm{m} \cdot \mathrm{s}^{-1}\right)$

$$
\text { TMP the transmembrane pressure }(\mathrm{Pa})
$$

$\mu_{p}$ the permeate dynamic viscosity (Pa.s)

$R_{h}$ the total resistance to permeation $\left(\mathrm{m}^{-1}\right)$.

\subsubsection{Definition of the optimal operating filtration conditions: flux-stepping experiments}

Pre-filtration tests were performed to define the optimal operating flux of the immersed membranes filtration system for each suspension. As stated before, membrane fouling is mainly governed by the equilibrium between convective and back-transport forces. Even if important permeate fluxes are generally needed to ensure the process sustainability, excessive fluxes can be counterproductive as they lead to important convective transports of foulant particles toward the membrane surface. Choosing an optimal permeate flux is therefore of crucial interest to control membrane fouling. Among all flux concepts that have been studied to guide permeate flux selection, critical and threshold fluxes concepts are particularly adopted when dealing with immersed membranes filtration [21]. 
151 Critical flux is defined as being the flux below which TMP remains strictly constant. According to many

152 studies, critical flux is generally really low and its determination is time consuming [21,41,42], which limits

153 its industrial application. In the light of this, the authors focused on the concept of threshold flux, defined

154 as being the flux at which the rate of fouling increases significantly. This flux concept is more applicable

155 for industrial applications, as less time is required for its determination and it generally matches with

156 acceptable value of fluxes.

157 Threshold flux identification was based on progressive increasing flux-steps under total recycle mode

158 (retentate and permeate were systematically returned to the feed tank) and on simultaneous TMP monitoring.

159 In this work, the filtration was initially operated at a constant permeate flux of $2 \mathrm{~L} \cdot \mathrm{h}^{-1} \cdot \mathrm{m}^{-2}$ for 10 minutes.

160 After 10 minutes, the flux was increased and the filtration was operated for another 10 minutes. Like so,

161 flux was gradually increased at 10-minutes intervals. The values of flux and flux-steps duration were chosen

162 according to values reported in the literature [43-45].

163 Based on the experimental results, the fouling rate increase was evaluated through the determination of

$164 \mathrm{dTMP} / \mathrm{dt}$ values for each constant flux-step, representing the TMP increase during the last 5 minutes of each

165 flux-step. A threshold value of $\mathrm{dTMP} / \mathrm{dt}=1.0 \times 10^{-5}$ bar. $\mathrm{s}^{-1}$ was chosen in accordance with values used in the

166 literature [43-46]. Thus, when dTMP/dt remained lower than $1.0 \times 10^{-5} \mathrm{bar}^{-1} \mathrm{~s}^{-1}$, fouling was considered as

167 being low. On the opposite, fouling increase was considered significant when dTMP/dt values were higher

168 than $1.0 \times 10^{-5}$ bar. $\mathrm{s}^{-1}$. Therefore, the threshold flux value was defined as being the highest flux at which

$169 \mathrm{dTMP} / \mathrm{dt}$ remained lower than $1.0 \times 10^{-5} \mathrm{bar} \cdot \mathrm{s}^{-1}$.

\subsubsection{Immersed membrane filtration performances}

172 Once the threshold flux was identified for each suspension, filtration experiments under batch concentration

173 mode (until Volume Reduction Ratio of 2) were performed at constant flux below or equal to the identified 174 threshold flux (sub-critical conditions).

175 The performances of immersed membranes configuration in terms of membrane fouling were estimated 176 through the monitoring of the TMP during the filtration running.

177 The performances of immersed membranes configuration in terms of selectivity were evaluated by 178 performing sampling on the initial feed suspensions and on the permeates resulting from their filtration 179 under batch concentration mode. Depending on the suspension, various separation objectives were expected 180 from microfiltration experiments (table 2). 
183

\begin{tabular}{cccc}
\hline Suspension & Grapefruit juice & Red Extract & Seed Extract \\
\hline & $\begin{array}{c}\text { Clarified permeate rich in } \\
\text { total phenolic } \\
\text { compounds }\end{array}$ & $\begin{array}{c}\text { Clarified permeate rich in } \\
\text { total phenolic } \\
\text { compounds } \\
\text { and anthocyanins }\end{array}$ & $\begin{array}{c}\text { Clarified permeate rich in } \\
\text { total phenolic } \\
\text { compounds } \\
\text { objectives }\end{array}$ \\
$\begin{array}{c}\text { Retentate concentrated } \\
\text { in }\end{array}$ & & \\
& $\begin{array}{c}\text { carotenoids (lycopene } \\
\text { and 8-carotene) }\end{array}$ & \\
&
\end{tabular}

185 The ability of immersed membranes filtration to produce a clarified permeate was measured through the analysis of turbidity loss, evaluated though the clarification ratio $C_{\text {clarif }}(\%)$, calculated as follows (equation 187 2):

$$
C_{\text {clarif }}=1-\frac{N T U_{p}}{N T U_{i}} \times 100
$$

The selectivity of the filtration towards valuable compounds was characterized through the retention ratio $C_{r e t}(\%)$ representing the percentage of targeted compound retained by the membrane (equation 3 ):

$$
C_{r e t}=1-\frac{C_{p}}{C_{i}} \times 100
$$

With $\quad N T U_{p}$ and $C_{p}$ the turbidity and the concentration of targeted compounds in the permeate $N T U_{i}$ and $C_{i}$ the turbidity and the concentration of targeted compounds in the initial feed suspension.

In the light of the above, various physicochemical and biochemical analyses were carried out for each suspension and related permeate.

Turbidity measurements were performed on water diluted extracts to fall in the turbidimeter precision domain ranging between 0 and 50 NTU (Hanna LP 2000, Hanna instruments, Szeged, Hungary).

Total phenolic content was measured by spectrophotometry, according to a modified Folin Ciocalteu method. Firstly, the suspensions were prepared in an ethanol/distilled water (25:75, v/v) solution. After the addition of $184 \mu \mathrm{L}$ of distilled water, $24 \mu \mathrm{L}$ of sample, $12 \mu \mathrm{L}$ of Folin Ciocalteu reagent and $30 \mu \mathrm{L}$ of 20 
$\%(w / v) \mathrm{Na}_{2} \mathrm{CO}_{3}$ solution in a 96-well microplate (MultiSkan Spectrum, Thermo Scientific), the resulting mixture was incubated at $25^{\circ} \mathrm{C}$ in the darkness for $1 \mathrm{~h}$. The absorbance was then measured at $765 \mathrm{~nm}$. Gallic acid was used as a standard for calibration. Results were expressed as milligrams gallic acid equivalent (GAE) per liter of sample.

Total monomeric anthocyanins content was determined using the $\mathrm{pH}$ differential method [47]. The sample absorbance was measured at $\mathrm{pH} 1.0$ and 4.5 at $510 \mathrm{~nm}$ (the wavelength of maximum absorbance) and at 700 $\mathrm{nm}$ to correct haze. Measurements were performed using a spectrophotometer (UV 2450, Shimadzu, Kyoto, Japan). Total monomeric anthocyanins were expressed as follows, as malvidin-3-glucoside equivalent (mg.L $\mathrm{L}^{-1}$ ) [48] (equation 4):

$$
C=\frac{A \times M W \times D F}{\varepsilon \times l} \times 10^{3}
$$

With $\quad M W$ the molecular weight $\left(463.3 \mathrm{~g} \cdot \mathrm{mol}^{-1}\right)$ and $\varepsilon$ the molar extinction coefficient (28 $000 \mathrm{~L} \cdot \mathrm{mol}^{-1} \cdot \mathrm{cm}^{-1}$ ) of malvidin-3-glucoside, respectively

$D F$ the dilution factor

$l$ the path length $(1.0 \mathrm{~cm})$

$A$ the sample absorbance, calculated as follows (equation 5):

$$
A=\left(A_{510}-A_{700}\right)_{p H 1.0}-\left(A_{510}-A_{700}\right)_{p H 4.5}
$$

Carotenoids (lycopene and B-carotene) content was evaluated thanks to an extraction step followed by HPLC analysis. Carotenoids were firstly extracted from the samples though two successive extraction steps using ethanol/hexane (4/3 (v/v) containing $0.1 \%$ of BHT as antioxidant) as extraction solvent, under stirring $[49,50]$. At each step, residue was separated from the liquid phase by filtration using an $n^{\circ} 2$ porosity filter funnel. Ethanol and hexane were successively used to wash the residue. Organic phases were transferred to a separating funnel and successively washed with $10 \%$ sodium chloride and distilled water. The aqueous layer was removed and the hexanic extract was collected and dried with a rotary evaporator at $30{ }^{\circ} \mathrm{C}$. The dried carotenoids extracts were then dissolved in $1 \mathrm{~mL}$ of dichloromethane/methyl tert-butyl ether/methanol solution $(50 / 40 / 10(\mathrm{v} / \mathrm{v} / \mathrm{v}))$. Secondly, HPLC analysis of carotenoids were conducted as described by Polidori et al. (2018) using an Agilent 1100 liquid chromatograph (Massy, France) equipped with a photodiode array detector and a $\mathrm{C}_{30}$ separation column $(250 \times 4.6 \mathrm{~mm}$ i.d., $5 \mu \mathrm{m}$ YMC, EUROP Gmbh, Germany) [50]. 


\subsection{Feed suspensions characterization}

The main physicochemical and chemical characteristics (dry matter (DM), turbidity (NTU), pH, Brix degree

239 ( ${ }^{\circ}$ Brix), dynamic viscosity $\left(\boldsymbol{\mu}_{\boldsymbol{s}}\right)$ and suspended insoluble solids (SIS)) of the three fruit-based suspensions

240 are given in table 3.

241

242

244

Table 3: Physicochemical characteristics of the studied suspensions.

\begin{tabular}{rccc}
\hline & Grapefruit juice & Red Extract & Seed Extract \\
DM (g. $\mathbf{L}^{-1}$ ) & $105.2 \pm 0.2$ & $34.5 \pm 0.2$ & $22.6 \pm 0.3$ \\
Turbidity (NTU) & $3720 \pm 230$ & $1000 \pm 70$ & $1560 \pm 250$ \\
pH (/) & $3.1 \pm 0.1$ & $3.6 \pm 0.1$ & $4.3 \pm 0.1$ \\
${ }^{\circ}$ Brix (g/100 g) & $9.9 \pm 0.1$ & $3.6 \pm 0.1$ & $3.1 \pm 0.1$ \\
$\boldsymbol{\mu}_{\boldsymbol{s}}$ (mPa.s) & $1.7 \pm 0.1$ & $1.4 \pm 0.1$ & $1.5 \pm 0.1$ \\
SIS (g. $\mathbf{L}^{-1}$ ) & $1.5 \pm 0.1$ & $1.6 \pm 0.1$ & $1.5 \pm 0.1$ \\
\hline
\end{tabular}

All assays were performed at $25 \pm 2{ }^{\circ} \mathrm{C}$ and values provided are the average of three replicates.

Among all studied products, grapefruit juice appeared to be the most different suspension with high turbidity, DM and Brix values. The two winery byproducts were quite similar, apart from a slightly lower DM value for Seed Extract and a higher turbidity value for Red Extract. These observations are consistent with the different raw materials and manufacturing processes related to each suspension. For the three suspensions, the SIS represented a very small part of the total dry matter with low SIS/DM ratios. It is a coherent observation, since a great part of their dry matter consists in sugar, estimated through the ${ }^{\circ}$ Brix.

\subsection{Definition of the optimal operating domain: flux-stepping experiments}

Figure 2 presents the TMP evolution as function of time during flux-stepping experiments performed on grapefruit juice (a), Red (b) and Seed Extracts (c). 

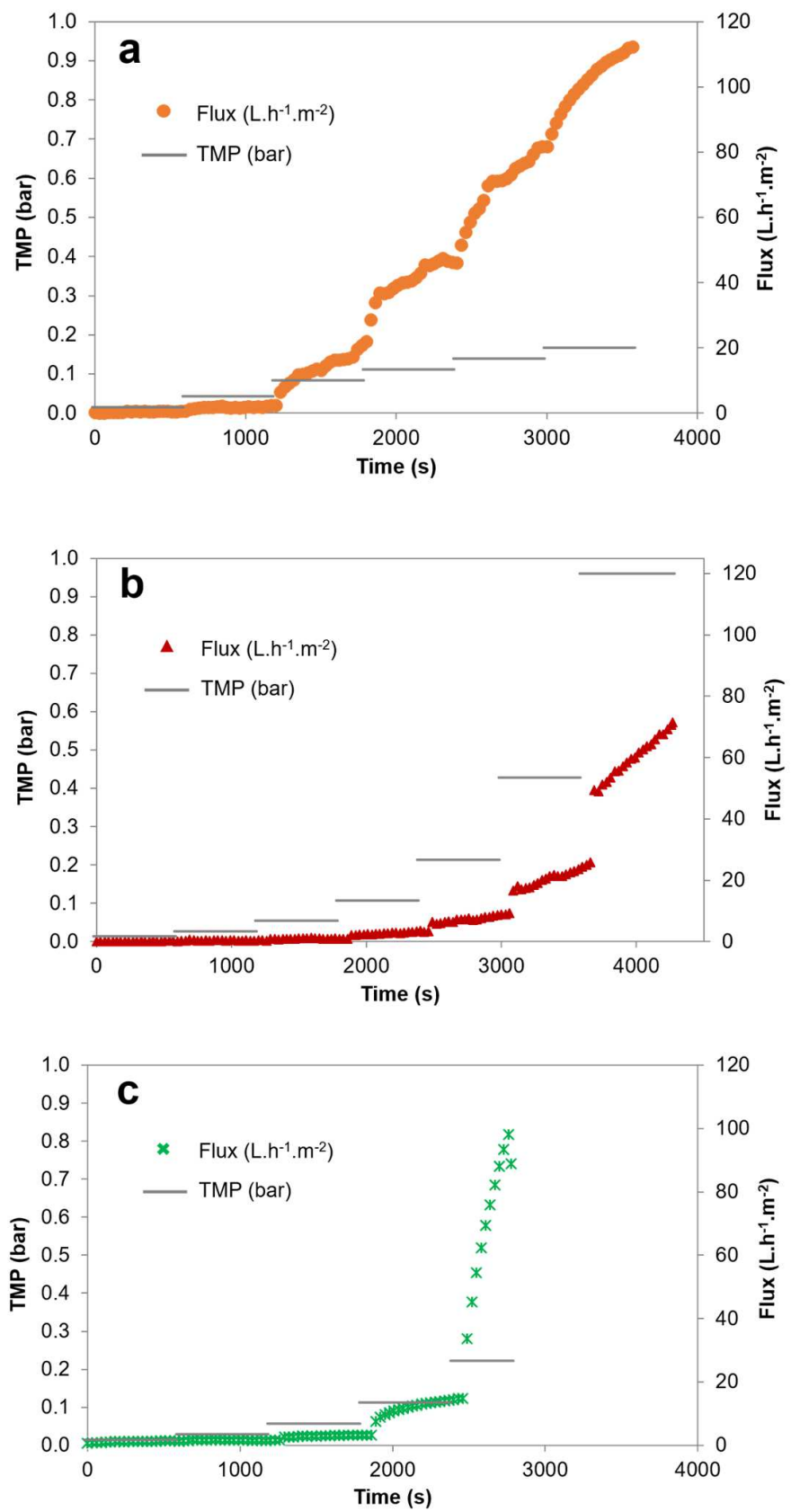

Figure 2: TMP versus time during flux-stepping experiments of grapefruit juice (a), Red Extract (b) and Seed Extract (c) using 0.1 $\mu \mathrm{m}$ PES hollow-fiber membranes.

For the three suspensions, it can be noticed that the TMP progressively increased in greater or lesser degree

264 for each flux-step, showing that fouling evolved differently depending on the imposed operating flux. Based

265 on these experimental results, the increase of the fouling rate was evaluated through the determination of dTMP/dt values for each constant flux-step and each suspension (figure 3). 


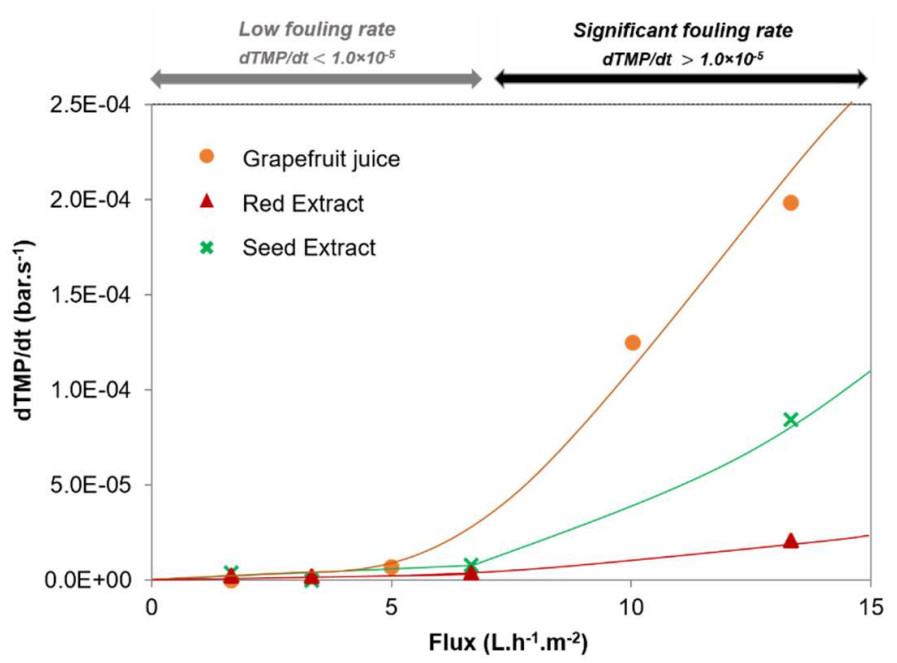

Figure 3: $d T M P / d t$ versus flux during flux-stepping experiments of grapefruit juice, Red Extract and Seed Extract using 0.1 um PES hollow-fiber membranes. Lines drawn to guide the eye.

For low operating fluxes, a similar fouling behavior was observed for the three suspensions with values of $\mathrm{dTMP} / \mathrm{dt}$ lower than the threshold value of $1.0 \times 10^{-5} \mathrm{bar} . \mathrm{s}^{-1}$ (low fouling rate). Contrariwise, once specific values of fluxes were exceeded, different fouling behaviors were identified. Concerning winery byproducts, a significant increase of the fouling rate was observed between 7 and $13 \mathrm{~L}^{-1} \mathrm{~h}^{-1} \cdot \mathrm{m}^{-2}$, with $\mathrm{dTMP} / \mathrm{dt}$ values reaching $2.1 \times 10^{-5}$ and $8.5 \times 10^{-5}$ bar. $\mathrm{s}^{-1}$ for Red and Seed Extracts, respectively. Therefore, the threshold flux was defined as being around $7 \mathrm{~L} \cdot \mathrm{h}^{-1} \cdot \mathrm{m}^{-2}$ for both winery byproducts in the studied operating conditions. Concerning grapefruit juice, the significant increase of the fouling rate was observed between 5 and 10 L.h ${ }^{1} \cdot \mathrm{m}^{-2}$ fluxes, with a dTMP/dt increase reaching $1.3 \times 10^{-4} \mathrm{bar}^{-1}{ }^{-1}$. Therefore, a threshold flux of around $5 \mathrm{~L} \cdot \mathrm{h}^{-}$ ${ }^{1} \cdot \mathrm{m}^{-2}$ was identified for this suspension.

It can be noticed that the threshold flux related to grapefruit juice seemed slightly lower than the ones identified for Red and Seed Extracts. Moreover, the fouling rate increased differently depending on the suspension. Above threshold flux, dTMP/dt values were substantially higher for grapefruit juice than for Seed Extract or Red Extract. These differences are not surprising since each suspension is characterized by specific biochemical and physicochemical properties. This result highlights the important impact of the suspension characteristics on membrane fouling and fouling mechanisms. However, despite these differences, the threshold fluxes of the three studied suspensions were in line with the threshold values reported for immersed membranes filtration in other fields. Indeed, threshold fluxes ranging between 5 and 
$10 \mathrm{~L} \cdot \mathrm{h}^{-1} \cdot \mathrm{m}^{-2}$ were reported during immersed membranes filtration of milk protein concentrate solutions [43],

292 activated sludge [44], alginate, yeast and bentonite solutions [45].

\subsection{Immersed membrane filtration performances}

\subsubsection{Membrane fouling}

296 For all suspensions, the membrane fouling evolution in immersed membranes configuration was evaluated 297 in sub-critical conditions, sustainable conditions for long-time filtration running. With a view to comparing 298 the fouling behavior of the three suspensions, a same constant flux of $5 \mathrm{~L} \cdot \mathrm{h}^{-1} \cdot \mathrm{m}^{-2}$ was chosen as operating 299 flux. Figure 4 presents the evolution of TMP as function of VRR during filtration of grapefruit juice, Red and Seed Extracts.

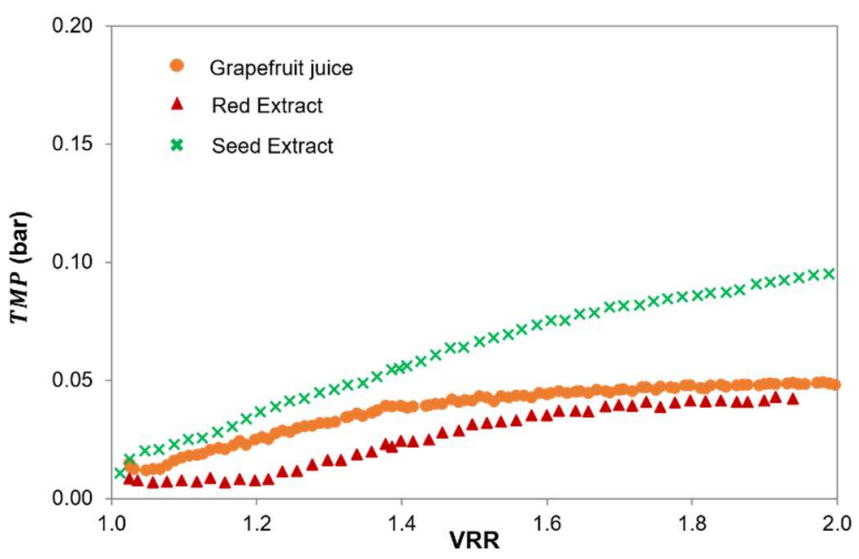

Figure 4: TMP as function of VRR during filtration of grapefruit juice, Red extract and Seed Extract (batch concentration mode).

For the three suspensions, a continuous increase of TMP was observed between VRR 1 and VRR 2, reflecting an increase in membrane fouling.

Different fouling behaviors can be distinguished for the three suspensions. At the beginning of the filtration (between VRR 1 and 1.2), TMP remained almost constant for Red Extract with TMP surrounding 8.0×10-3 bar and dTMP/dt close to zero. Contrariwise, an important and immediate fouling was observed for Seed Extract and grapefruit juice, with TMP increasing from $1.0 \times 10^{-2}$ to $3.7 \times 10^{-2}$ bar and from $1.5 \times 10^{-2}$ to $2.5 \times 10^{-}$ ${ }^{2}$ bar, respectively. Starting VRR 1.2, fouling increased for Red Extract while it stabilized for grapefruit juice leading to a final TMP of around $4.0 \times 10^{-2}$ bar at VRR 2 for both suspensions. Concerning Seed Extract filtration, a continuous fouling was observed throughout the remainder of the filtration operation, with TMP reaching around $1.0 \times 10^{-1}$ bar at VRR 2 . 
314 These differences of fouling behavior might be related to the physicochemical characteristics of each 315 suspension (table 3). Indeed, the three suspensions presented different dynamic viscosities, $\mathrm{pH}, \mathrm{DM}$, Brix 316 and turbidity and these parameters are known for having a significant impact on membrane fouling [40]. 317 However, considering the complexity of these biological suspensions, these physicochemical properties are 318 not sufficient to explain the different fouling behaviors of the studied suspensions. Indeed, membrane 319 fouling results from complex interactions between the suspension compounds and the membrane and 320 between the suspension compounds themselves [51,52]. These phenomena are governed not only by the 321 operating conditions of the filtration operation and the physicochemical characteristics of the suspension, 322 but also by the biochemical nature of the suspension compounds. Hence, the differences of fouling behavior 323 between the studied suspensions might also be strongly related to the specific biochemical properties of 324 each suspension.

In order to estimate the importance of the fouling rate increase during a running operation, dTMP/dt were calculated for each suspension. Between VRR 1 and VRR 2, dTMP/dt values remained lower than the threshold value for the three suspensions, with $\mathrm{dTMP} / \mathrm{dt}$ of $5.3 \times 10^{-6}, 5.5 \times 10^{-6}$ and $5.9 \times 10^{-6}$ bar. $\mathrm{s}^{-1}$ for grapefruit juice, Red and Seed Extracts, respectively. In the light of this, it seems that the fouling rates remained sustainable throughout the filtration operation, in batch concentration mode. This observation supports the interest of using the critical or threshold flux concept as pre-filtration test in order to define the optimal operating conditions prior to effective filtration experiments.

\subsubsection{Membrane selectivity}

335 The selectivity of immersed membranes was evaluated trough the characterization of turbidity loss 336 (clarification), the retention of total phenolic compounds for the three suspensions, and the retention of 337 carotenoids for grapefruit juice.

338 Concerning clarification efficiency, $C_{\text {clarif }}$ of $99.9 \%, 99.5 \%$ and $99.3 \%$ were obtained for grapefruit juice, 339 Red and Seed Extracts, respectively, with permeates turbidities lower than 5 NTU for the three suspensions. 340 These results are in accordance with values reported in the literature during microfiltration of melon and 341 pomegranate juices [2,12]. For the three suspensions, immersed membranes filtration allowed decreasing 342 significantly the initial turbidity of the suspension leading to a clarified permeate. 
Concerning phenolic compounds, initial feed suspensions presented very different concentrations of total phenolic compounds, with 145, 4076 and $5517 \mathrm{mg}$ GAE per liter of grapefruit, Red Extract and Seed Extract, respectively. These quantitative differences between grapefruit juice and winery byproducts are consistent since winery byproduct are known for their particular richness in phenolic compounds [38,39]. As mentioned before, these phenolic compounds include, among others, naringin and narirutin for grapefruit juice, tannins for Red and Seed Extracts and anthocyanins for Red Extract. Anthocyanins were also quantified in Red Extract and there concentration was around $560 \mathrm{mg}$ malvidin-3-glucoside. $\mathrm{L}^{-1}$ which is in the range of what is generally reported in the literature (from 300 to $900 \mathrm{mg}$ malvidin-3-glucoside. $\mathrm{L}^{-1}$ ) $[48,53]$. These differences concerning at the same time the type and the concentration of bioactive compounds in each suspension could have an impact on the membrane selectivity during the filtration operation. Table 4 presents the $C_{\text {ret }}$ regarding bioactive compounds specific to each studied suspension.

Table 4: Retention ratios (\%) regarding total phenolic compounds, anthocyanins, b-carotene, lycopene during grapefruit juice, Red and Seed Extracts microfiltration.

358

\begin{tabular}{rccc}
\hline & Grapefruit juice & Red Extract & Seed Extract \\
\hline Total phenolic compounds & 8 & 14 & 3 \\
Anthocyanins & $/$ & 17 & $/$ \\
B-carotene & 96 & $/$ & $/$ \\
Lycopene & 96 & $/$ & $/$ \\
\hline
\end{tabular}

359

360

361

362

363

364

365

366

367

368

369

370

371

Regardless of the suspension, phenolic compounds (including anthocyanins) were mainly recovered in the permeate with low $C_{\text {ret }}$ ranging between 3 and $17 \%$. Similar results have been reported during microfiltration of pineapple juice (retention of $7 \%$ of total phenolic content [14]), pomegranate juice (retention of $16.5 \%$ of total polyphenols and $11.7 \%$ of anthocyanins [54]), red raspberry juice (retention of $16 \%$ of anthocyanins [17]). This is a consistent observation since most of phenolic compounds are smaller than the membrane pore size $(0.1 \mu \mathrm{m})$ with molecular weight generally ranging between 300 and $3000 \mathrm{Da}$ [55], even though some highly polymerized tannins (condensed tannins) have been reported to reach 20,000 Da [56]. However, membrane selectivity to phenolic compounds cannot be discussed only in terms of their nominal molecular weight. Indeed, in the case of winery byproducts, low molecular weight phenolic compounds can interact with each other or with other compounds, leading to the formation of complexes with higher average size (e.g. tannin-anthocyanin, anthocyanin-anthocyanin, tannin-proteins complexes) [8]. Thus, the higher $C_{r e t}$ observed for Red Extract phenolic compounds (14\%) and anthocyanins (17\%) could be explained by complexation phenomena, leading to the formation of compounds larger than the 
membrane pore size. The partial retention of phenolic compounds and anthocyanins could also be related their adsorption on/in the membrane layer [51].

Concerning carotenoids ( $\beta$-carotene and lycopene), the concentration of lycopene was higher than that of beta-carotene in grapefruit, with respective concentrations of 1.75 et $0.18 \mathrm{mg} . \mathrm{L}^{-1}$. These differences of concentrations did not have an influence on $C_{r e t}$ ratios, which were greater than $96 \%$ for both compounds. Despite their relatively low molecular weight (536.87 g. mol ${ }^{-1}$ ), almost all carotenoids were retained by the membrane. This phenomenon has been reported in many studied and is explained by the strong association of carotenoids with the cell fragments membranes (i.e. pulp) due to their hydrophobicity [2]. Therefore, carotenoids are mainly concentrated in the retentate during fruit juice microfiltration $[2,50]$.

In the light of the above, immersed membranes filtration allowed producing (i) a permeate rich in phenolic compounds and clarified for the three suspensions and (ii) a retentate concentrated in carotenoids for grapefruit juice.

\subsection{Comparison with conventional cross-flow filtration using side-stream membranes}

The previous analysis allowed characterizing the performances of immersed membranes configuration in terms of productivity and selectivity. In order to validate the efficiency of immersed membranes configuration for fruit-based suspensions microfiltration, previous productivity and selectivity results were compared with the performances of cross-flow filtration using side-stream tubular membranes. Indeed, this filtration configuration remains the most used for fruit juices microfiltration [2,16-20]. Cross-flow filtration experiments were performed under batch mode concentration (until VRR 2), using operating conditions generally used when dealing with fruit-based suspensions microfiltration $(0.1 \mu \mathrm{m}$ inorganic tubular membranes, constant pressure of 1.5 bar $[2,16,18,57])$. The cross-flow velocity in each membrane and in the loop tubes (with diameter close to the membrane one) was around $5 \mathrm{~m} \cdot \mathrm{s}^{-1}$, corresponding to a Reynolds number and a membrane shear rate of 7300 and $22000 \mathrm{~s}^{-1}$, respectively (turbulent flow) ([57]).

Steady-state fluxes (flux decay was observed for the three suspensions, followed by a pseudo-equilibrium of the flux) of $80 \mathrm{~L} \cdot \mathrm{h}^{-1} \cdot \mathrm{m}^{-2}, 30 \mathrm{~L} \cdot \mathrm{h}^{-1} \cdot \mathrm{m}^{-2}$ and $24 \mathrm{~L} \cdot \mathrm{h}^{-1} \cdot \mathrm{m}^{-2}$ were obtained for grapefruit juice, Red and Seed Extracts, respectively. These different flux values are in line with permeate flux values reported during microfiltration of citrus fruit juices $\left(20-80 \mathrm{~L} \cdot \mathrm{h}^{-1} \cdot \mathrm{m}^{-2}[57,58]\right)$ and winery byproducts $\left(35 \mathrm{~L} \cdot \mathrm{h}^{-1} \cdot \mathrm{m}^{-2}[38,59]\right)$. However, it is interesting to note that the ranking of the fouling potential obtained during cross-flow filtration experiments was slightly different than the one observed during immersed membranes filtration experiments. While Red Extract presented a low fouling potential close to that of grapefruit juice during 
427 In order to compare the selectivity of both configurations, $C_{\text {clarif }}$ and $C_{r e t}$ were calculated for cross-flow 428 filtration experiments, based on analysis performed on the permeates collected at the end of the previous

immersed membranes filtration experiments, it was one of the most foulant suspension during cross-flow filtration experiments, with low flux $\left(30 \mathrm{~L} \cdot \mathrm{h}^{-1} \cdot \mathrm{m}^{-2}\right)$ compared to grapefruit juice. These differences of fouling behavior might be related to the different hydrodynamic conditions of each studied filtration configuration. However, an extensive characterization of the fouling behaviors of these suspensions (fouling mechanisms, involved particles, etc.) while using immersed membranes filtration or cross-flow filtration is necessary to go further on this path.

Concerning productivity, fluxes obtained for the three suspensions during cross-flow filtration were much higher ( 5 to 16 times greater) than the threshold flux of $5 \mathrm{~L} \cdot \mathrm{h}^{-1} \cdot \mathrm{m}^{-2}$ identified during immersed membranes filtration. These differences of order of magnitude are in line with the fluxes generally reported for these two configurations. Xue et al. (2015) compared the performances of an immersed membranes system with a side-stream one (cross-flow) during waste leachate treatment and reported fluxes almost 20 times higher when using cross-flow filtration [60]. Indeed, cross-flow filtration is an intensive process that works with high shear rates to ensure a high productivity but requires high energy consumption and investment cost. On the opposite, immersed membranes system can be considered as an extensive process (gentle operating conditions, low fluxes) for which productivity is generally improved by increasing the membrane surface thanks to low investment costs and limited energy consumption [61,62]. Despite its relatively low productivity, immersed membranes configuration could offer interesting applications in fruit juices and agro-food byproducts processing. Indeed, this simple processing system might be a convenient filtration configuration for small agro-food producers with limited investment capacities or for the valorization byproducts with low added-value. However, further analysis are needed to confirm these suggestions, notably concerning the process selectivity.

filtration experiments (batch concentration mode) and on the feed suspensions. $C_{\text {clarif }}$ similar to the ones obtained for immersed membranes filtration were observed at the end of cross-flow filtration experiments (99.8\%, $96.4 \%$ and $97.3 \%$ for grapefruit juice, Red and Seed Extracts, respectively). Concerning $C_{r e t}$, slight differences were observed between immersed membranes filtration and cross-flow filtration (figure 5). 
436

437

438

439 Concerning grapefruit juice carotenoids, both configurations presented very close $C_{\text {ret }}(93-99 \%)$. As

Figure 5: Comparison of immersed membranes filtration (a) and cross-flow filtration (b) selectivity. during immersed membranes filtration, most of carotenoids were concentrated in the retentate during crossflow filtration experiments.

When comparing phenolic compounds for the three suspensions and anthocyanins for Red Extract, crossflow filtration presented higher $C_{r e t}(10-33 \%)$ than immersed membranes filtration (3-17\%).

These differences could be explained by adsorption mechanisms occurring on the mineral tubular membrane used for cross-flow filtration experiments, as reported by Vladisavljević et al. (2013) [17]. Moreover, the differences of $C_{\text {ret }}$ could also be related to the different hydrodynamic conditions specific to each configuration. Indeed, the high cross-flow velocities and high TMP specific to cross-flow filtration might enhance the interactions between the phenolic compounds and between phenolic compounds and other Red Extract compounds, leading to the formation of complexes larger than the membrane average pore diameter $[63,64]$. Considering the many differences between both configurations, it is difficult to state which phenomenon is responsible of $C_{\text {ret }}$ differences.

To sum up, immersed membranes filtration allowed producing retentate and permeate of quality as least as good as the one obtained with conventional cross-flow filtration. Concerning the process productivity, crossflow filtration was the most interesting filtration configuration in terms of flux values for the three studied suspensions. However, the productivity of immersed membranes configuration could be easily increased by increasing the membrane surface (low cost of the membranes and great packing density) and thanks to the low energy consumption of this system. Moreover, immersed membranes system could find interesting application for small production units thanks to its compactness, easy handling and mobility.
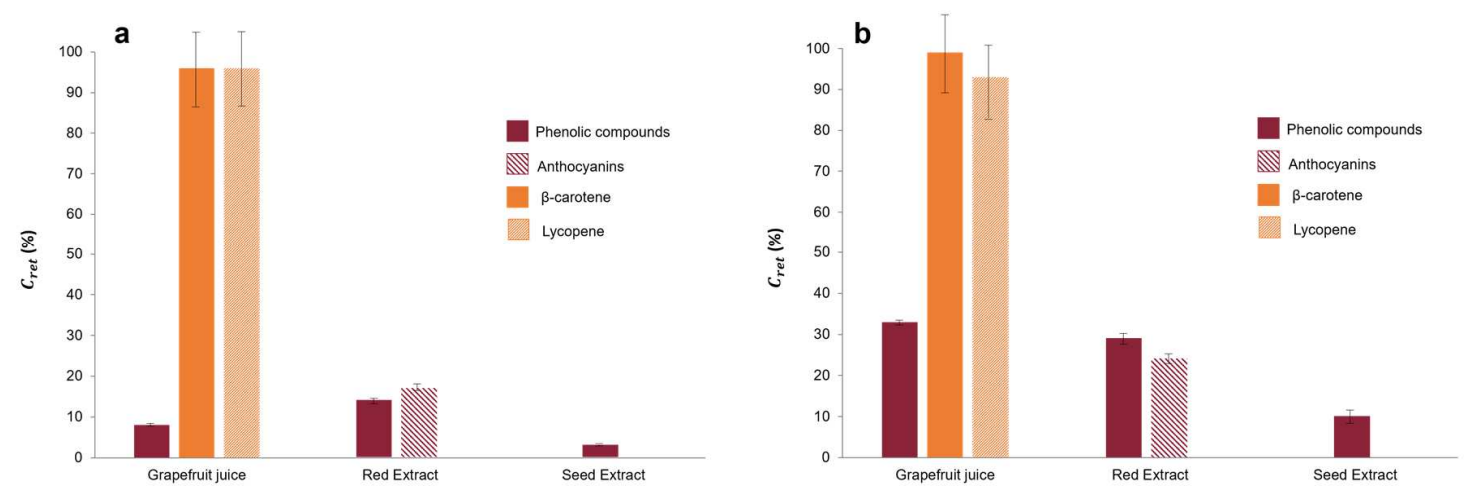


\section{Conclusion}

460 The aim of this work was to investigate the possibility of using an immersed membranes configuration for

461 the microfiltration of fruit-based suspensions. The study focused on three different agro-food suspensions,

462 for which microfiltration is widely used for clarification and concentration purpose, a grapefruit juice and

463 two winery byproducts. The performances of a pilot-scale immersed membranes system were characterized

464 in terms of membrane permeability (membrane fouling, permeate flux) and selectivity (clarification,

465 concentration of targeted compounds).

466 Flux-stepping experiments performed under total recycle mode followed by filtration experiments under 467 batch concentration mode allowed defining and validating the optimal operating domains of the studied 468 system. The optimal permeate flux of immersed membranes configuration was found to be around $5-7$ $469 \mathrm{~L} \cdot \mathrm{h}^{-1} \cdot \mathrm{m}^{-2}$ for the three studied suspensions, which is in line with permeate fluxes reported in other fields 470 where immersed configurations have been widely and successfully used. Selectivity analysis showed that 471 immersed membranes filtration allowed reaching the selectivity goals specific to each suspension by 472 producing (i) a clarified permeate rich in phenolic compounds and (ii) a retentate concentrated in carotenoids 473 for grapefruit juice. Finally, immersed membranes filtration productivity and selectivity results were 474 compared with performances of conventionally used cross-flow filtration with tubular membranes. The 475 main outcomes were that immersed membranes filtration allowed producing retentate and permeate with 476 quality as least as good as the one related to conventional cross-flow filtration. Concerning the process 477 productivity, cross-flow filtration allowed reaching high fluxes compared to immersed membranes 478 filtration. These differences were in line with the respective order of magnitude of fluxes reported for both 479 configurations. However, thanks to its high compactness, easy handling and mobility, low investment and 480 operational costs, immersed membranes configuration could find interesting applications in small 481 production units of fruit juices and industries dealing with the valorization of byproducts with low added482 value. Immersed membranes configuration could be an affordable and simple process to perform the in situ 483 clarification/concentration of fruit-based suspensions, limiting loss and wastage due to processing delay.

484 All these findings offer new prospects for immersed membranes configuration applied to fruit-based 485 suspensions microfiltration. Further investigations would be of great interest to get more insight into the 486 involved fouling mechanisms occurring during immersed membranes filtration of fruit-based suspensions. 
[1] R.C. de Oliveira, R.C. Docê, S.T.D. de Barros, Clarification of passion fruit juice by microfiltration: Analyses of operating parameters, study of membrane fouling and juice quality, Journal of Food Engineering. 111 (2012) 432-439. doi:10.1016/j.jfoodeng.2012.01.021.

[2] F. Vaillant, M. Cisse, M. Chaverri, A. Perez, M. Dornier, F. Viquez, C. Dhuique-Mayer, Clarification and concentration of melon juice using membrane processes, Innovative Food Science \& Emerging Technologies. 6 (2005) 213-220. doi:10.1016/j.ifset.2004.11.004.

[3] A. Cassano, C. Conidi, E. Drioli, Physico-chemical parameters of cactus pear (Opuntia ficus-indica) juice clarified by microfiltration and ultrafiltration processes, Desalination. 250 (2010) 1101-1104. doi:10.1016/j.desal.2009.09.117.

498

[4] L. Carneiro, I. dos Santos Sa, F. dos Santos Gomes, V.M. Matta, L.M.C. Cabral, Cold sterilization and clarification of pineapple juice by tangential microfiltration, Desalination. 148 (2002) 93-98. doi:10.1016/S0011-9164(02)00659-8.

501

502

503

504

505

506

507

508

509

510

511

512

513

514

515

516

517

518

519

520

521

522

[5] M.T.C. Machado, S. Trevisan, J.D.R. Pimentel-Souza, G.M. Pastore, M.D. Hubinger, Clarification and concentration of oligosaccharides from artichoke extract by a sequential process with microfiltration and nanofiltration membranes, Journal of Food Engineering. 180 (2016) 120-128. doi:10.1016/j.jfoodeng.2016.02.018.

[6] R. Castro-Muñoz, J. Yáñez-Fernández, V. Fíla, Phenolic compounds recovered from agro-food byproducts using membrane technologies: An overview, Food Chemistry. (2016). doi:10.1016/j.foodchem.2016.07.030.

[7] C.D. dos Santos, R.K. Scherer, A.S. Cassini, L.D.F. Marczak, I.C. Tessaro, Clarification of red beet stalks extract by microfiltration combined with ultrafiltration, Journal of Food Engineering. 185 (2016) 3541. doi:10.1016/j.jfoodeng.2016.03.031.

[8] Y. El Rayess, C. Albasi, P. Bacchin, P. Taillandier, J. Raynal, M. Mietton-Peuchot, A. Devatine, Crossflow microfiltration applied to oenology: A review, Journal of Membrane Science. 382 (2011) 1-19. doi:10.1016/j.memsci.2011.08.008.

[9] C. Bhattacharjee, V.K. Saxena, S. Dutta, Fruit juice processing using membrane technology: A review, Innovative Food Science \& Emerging Technologies. 43 (2017) 136-153. doi:10.1016/j.ifset.2017.08.002.

[10] T. Miyoshi, K. Yuasa, T. Ishigami, S. Rajabzadeh, E. Kamio, Y. Ohmukai, D. Saeki, J. Ni, H. Matsuyama, Effect of membrane polymeric materials on relationship between surface pore size and membrane fouling in membrane bioreactors, Applied Surface Science. 330 (2015) 351-357. doi:10.1016/j.apsusc.2015.01.018.

[11] L. Dahdouh, C. Wisniewski, J. Ricci, L. Vachoud, M. Dornier, M. Delalonde, Rheological study of orange juices for a better knowledge of their suspended solids interactions at low and high concentration, Journal of Food Engineering. 174 (2016) 15-20. doi:10.1016/j.jfoodeng.2015.11.008.

[12] H. Mirsaeedghazi, Z. Emam-Djomeh, S.M. Mousavi, A. Aroujalian, M. Navidbakhsh, Clarification of pomegranate juice by microfiltration with PVDF membranes, Desalination. 264 (2010) 243-248. doi:10.1016/j.desal.2010.03.031.

[13] A. Laorko, Z. Li, S. Tongchitpakdee, W. Youravong, Effect of gas sparging on flux enhancement and phytochemical properties of clarified pineapple juice by microfiltration, Separation and Purification Technology. 80 (2011) 445-451. doi:10.1016/j.seppur.2011.05.024.

[14] A. Laorko, Z. Li, S. Tongchitpakdee, S. Chantachum, W. Youravong, Effect of membrane property and operating conditions on phytochemical properties and permeate flux during clarification of 
pineapple juice, Journal of Food Engineering. $100 \quad$ (2010) 514-521. doi:10.1016/j.jfoodeng.2010.04.039.

[15] J. Luo, X. Hang, W. Zhai, B. Qi, W. Song, X. Chen, Y. Wan, Refining sugarcane juice by an integrated membrane process: Filtration behavior of polymeric membrane at high temperature, Journal of Membrane Science. 509 (2016) 105-115. doi:10.1016/j.memsci.2016.02.053.

[16] W. Youravong, Z. Li, A. Laorko, Influence of gas sparging on clarification of pineapple wine by microfiltration, Journal of Food Engineering. $96 \quad$ (2010) 427-432. doi:10.1016/j.jfoodeng.2009.08.021.

[17] G.T. Vladisavljević, P. Vukosavljević, M.S. Veljović, Clarification of red raspberry juice using microfiltration with gas backwashing: A viable strategy to maximize permeate flux and minimize a loss of anthocyanins, Food and Bioproducts Processing. 91 (2013) 473-480. doi:10.1016/j.fbp.2013.05.004.

[18] B.-J. Wang, T.-C. Wei, Z.-R. Yu, Effect of operating temperature on component distribution of West Indian cherry juice in a microfiltration system, LWT - Food Science and Technology. 38 (2005) 683689. doi:10.1016/j.Iwt.2004.09.002.

[19] F. Vaillant, A.M. Pérez, O. Acosta, M. Dornier, Turbidity of pulpy fruit juice: A key factor for predicting cross-flow microfiltration performance, Journal of Membrane Science. 325 (2008) 404-412. doi:10.1016/j.memsci.2008.08.003.

[20] F. Vaillant, E. Jeanton, M. Dornier, G.. O’Brien, M. Reynes, M. Decloux, Concentration of passion fruit juice on an industrial pilot scale using osmotic evaporation, Journal of Food Engineering. 47 (2001) 195-202. doi:10.1016/S0260-8774(00)00115-1.

[21] J. Luo, Z. Zhu, L. Ding, O. Bals, Y. Wan, M.Y. Jaffrin, E. Vorobiev, Flux behavior in clarification of chicory juice by high-shear membrane filtration: Evidence for threshold flux, Journal of Membrane Science. 435 (2013) 120-129. doi:10.1016/j.memsci.2013.01.057.

[22] C. Wisniewski, A. Grasmick, A. Leon Cruz, Critical particle size in membrane bioreactors: Case of a denitrifying bacterial suspension, Journal of Membrane Science. 178 (2000) 141-150. doi:10.1016/S0376-7388(00)00487-7.

[23] J.-S. Kim, C.-H. Lee, I.-S. Chang, Effect of pump shear on the performance of a crossflow membrane bioreactor, Water Research. 35 (2001) 2137-2144. doi:10.1016/S0043-1354(00)00495-4.

[24] J.-B. Castaing, A. Massé, M. Pontié, V. Séchet, J. Haure, P. Jaouen, Investigating submerged ultrafiltration (UF) and microfiltration (MF) membranes for seawater pre-treatment dedicated to total removal of undesirable micro-algae, Desalination. $253 \quad$ (2010) 71-77. doi:10.1016/j.desal.2009.11.031.

[25] J.-B. CASTAING, A. MASSE, V. SECHET, N.-E. SABIRI, M. PONTIE, J. HAURE, P. JAOUEN, Immersed hollow fibres microfiltration (MF) for removing undesirable micro-algae and protecting semi-closed aquaculture basins, Desalination. 276 (2011) 386-396. doi:10.1016/j.desal.2011.03.081.

[26] L. Marbelia, M. Mulier, D. Vandamme, K. Muylaert, A. Szymczyk, I.F.J. Vankelecom, Polyacrylonitrile membranes for microalgae filtration: Influence of porosity, surface charge and microalgae species on membrane fouling, Algal Research. 19 (2016) 128-137. doi:10.1016/j.algal.2016.08.004.

[27] F. Fatone, P. Battistoni, D. Bolzonella, P. Pavan, F. Cecchia, Long-term experience with an automatic process control for nitrogen removal in membrane bioreactors, Desalination. 227 (2008) 72-84. doi:10.1016/j.desal.2007.05.036.

[28] L. Clouzot, N. Roche, B. Marrot, Effect of membrane bioreactor configurations on sludge structure and microbial activity, Bioresource Technology. $102 \quad$ (2011) 975-981. doi:10.1016/j.biortech.2010.09.058. 
[29] R.R. Singhania, G. Christophe, G. Perchet, J. Troquet, C. Larroche, Immersed membrane bioreactors: An overview with special emphasis on anaerobic bioprocesses, Bioresource Technology. 122 (2012) 171-180. doi:10.1016/j.biortech.2012.01.132.

[30] P. Côté, H. Buisson, C. Pound, G. Arakaki, Immersed membrane activated sludge for the reuse of municipal wastewater, Desalination. 113 (1997) 189-196. doi:10.1016/S0011-9164(97)00128-8.

[31] X. Li, J. Li, Z. Cui, Y. Yao, Modeling of filtration characteristics during submerged hollow fiber membrane microfiltration of yeast suspension under aeration condition, Journal of Membrane Science. 510 (2016) 455-465. doi:10.1016/j.memsci.2016.03.003.

[32] B. Lesjean, E.H. Huisjes, Survey of the European MBR market: trends and perspectives, Desalination. 231 (2008) 71-81. doi:10.1016/j.desal.2007.10.022.

[33] M.W. Cheong, S.Q. Liu, W. Zhou, P. Curran, B. Yu, Chemical composition and sensory profile of pomelo (Citrus grandis (L.) Osbeck) juice, Food Chemistry. 135 (2012) 2505-2513. doi:10.1016/j.foodchem.2012.07.012.

[34] H. Kelebek, Sugars, organic acids, phenolic compositions and antioxidant activity of Grapefruit (Citrus paradisi) cultivars grown in Turkey, Industrial Crops and Products. 32 (2010) 269-274. doi:10.1016/j.indcrop.2010.04.023.

[35] L. Castro-Vazquez, M.E. Alañón, V. Rodríguez-Robledo, M.S. Pérez-Coello, I. Hermosín-Gutierrez, M.C. Díaz-Maroto, J. Jordán, M.F. Galindo, M. del M. Arroyo-Jiménez, Bioactive Flavonoids, Antioxidant Behaviour, and Cytoprotective Effects of Dried Grapefruit Peels (Citrus paradisi Macf.), Oxidative Medicine and Cellular Longevity. 2016 (2016) 8915729. doi:10.1155/2016/8915729.

[36] M.-U.-D. Khan, G. Mackinney, Carotenoids in Grapefruit, Citrus Paradisi, Plant Physiology. 28 (1953) 550-552.

[37] C. Rouquié, L. Dahdouh, M. Delalonde, C. Wisniewski, An innovative lab-scale strategy for the evaluation of Grape Processing Residues (GPR) filterability: Application to GPR valorization by ultrafiltration, Innovative Food Science \& Emerging Technologies. (2017). doi:10.1016/j.ifset.2017.03.015.

[38] A. Giacobbo, J.M. do Prado, A. Meneguzzi, A.M. Bernardes, M.N. de Pinho, Microfiltration for the recovery of polyphenols from winery effluents, Separation and Purification Technology. 143 (2015) 12-18. doi:10.1016/j.seppur.2015.01.019.

[39] N. Balasundram, K. Sundram, S. Samman, Phenolic compounds in plants and agri-industrial byproducts: Antioxidant activity, occurrence, and potential uses, Food Chemistry. 99 (2006) 191-203. doi:10.1016/j.foodchem.2005.07.042.

[40] L. Dahdouh, C. Wisniewski, A. Kapitan-Gnimdu, A. Servent, M. Dornier, M. Delalonde, Identification of relevant physicochemical characteristics for predicting fruit juices filterability, Separation and Purification Technology. 141 (2015) 59-67. doi:10.1016/j.seppur.2014.11.030.

[41] R.W. Field, G.K. Pearce, Critical, sustainable and threshold fluxes for membrane filtration with water industry applications, Advances in Colloid and Interface Science. 164 (2011) 38-44. doi:10.1016/j.cis.2010.12.008.

[42] D.J. Miller, S. Kasemset, D.R. Paul, B.D. Freeman, Comparison of membrane fouling at constant flux and constant transmembrane pressure conditions, Journal of Membrane Science. 454 (2014) 505515. doi:10.1016/j.memsci.2013.12.027.

[43] M. Chai, Y. Ye, V. Chen, Separation and concentration of milk proteins with a submerged membrane vibrational system, Journal of Membrane Science. 524 (2017) 305-314. doi:10.1016/j.memsci.2016.11.043. 
[44] P. Le Clech, B. Jefferson, I.S. Chang, S.J. Judd, Critical flux determination by the flux-step method in a submerged membrane bioreactor, Journal of Membrane Science. 227 (2003) 81-93. doi:10.1016/j.memsci.2003.07.021.

[45] A. Kola, Y. Ye, A. Ho, P. Le-Clech, V. Chen, Application of low frequency transverse vibration on fouling limitation in submerged hollow fibre membranes, Journal of Membrane Science. 409-410 (2012) 5465. doi:10.1016/j.memsci.2012.03.017.

[46] M. Dalmau, H. Monclús, S. Gabarrón, I. Rodriguez-Roda, J. Comas, Towards integrated operation of membrane bioreactors: Effects of aeration on biological and filtration performance, Bioresource Technology. 171 (2014) 103-112. doi:10.1016/j.biortech.2014.08.031.

[47] J. Lee, R.W. Durst, R.E. Wrolstad, Determination of total monomeric anthocyanin pigment content of fruit juices, beverages, natural colorants, and wines by the $\mathrm{pH}$ differential method: collaborative study., J AOAC Int. 88 (2005) 1269-1278.

[48] A. Bimpilas, M. Panagopoulou, D. Tsimogiannis, V. Oreopoulou, Anthocyanin copigmentation and color of wine: The effect of naturally obtained hydroxycinnamic acids as cofactors, Food Chemistry. 197 (2016) 39-46. doi:10.1016/j.foodchem.2015.10.095.

[49] C. Dhuique-Mayer, M. Tbatou, M. Carail, C. Caris-Veyrat, M. Dornier, M.J. Amiot, Thermal Degradation of Antioxidant Micronutrients in Citrus Juice: Kinetics and Newly Formed Compounds, J. Agric. Food Chem. 55 (2007) 4209-4216. doi:10.1021/jf0700529.

[50] J. Polidori, C. Dhuique-Mayer, M. Dornier, Crossflow microfiltration coupled with diafiltration to concentrate and purify carotenoids and flavonoids from citrus juices, Innovative Food Science \& Emerging Technologies. 45 (2018) 320-329. doi:10.1016/j.ifset.2017.11.015.

[51] A. Cassano, G. De Luca, C. Conidi, E. Drioli, Effect of polyphenols-membrane interactions on the performance of membrane-based processes. A review, Coordination Chemistry Reviews. 351 (2017) 45-75. doi:10.1016/j.ccr.2017.06.013.

[52] D. Layal, D. Michèle, R. Julien, R. Emilie, W. Christelle, Influence of high shear rate on particles size, rheological behavior and fouling propensity of fruit juices during crossflow microfiltration: Case of orange juice, Innovative Food Science \& Emerging Technologies. (2018). doi:10.1016/j.ifset.2018.07.006.

[53] M. Kharadze, I. Japaridze, A. Kalandia, M. Vanidze, Anthocyanins and antioxidant activity of red wines made from endemic grape varieties, Annals of Agrarian Science. (2018). doi:10.1016/j.aasci.2018.04.006.

[54] A. Cassano, C. Conidi, E. Drioli, Clarification and concentration of pomegranate juice (Punica granatum L.) using membrane processes, Journal of Food Engineering. 107 (2011) 366-373. doi:10.1016/j.jfoodeng.2011.07.002.

[55] Bate-Smith, Swain, Flavonoid compounds, Comparative Biochemistry. III. New York: Academic Press. (1962) 75-809.

[56] K. Khanbabaee, Tannins: Classification and Definition, (n.d.) 9.

[57] D. Layal, W. Christelle, R. Julien, K.-G. André, D. Manuel, D. Michèle, Development of an original labscale filtration strategy for the prediction of microfiltration performance: Application to orange juice clarification, Separation and Purification Technology. 156, Part 1 (2015) 42-50. doi:10.1016/j.seppur.2015.10.010.

[58] B.K. Nandi, R. Uppaluri, M.K. Purkait, Identification of optimal membrane morphological parameters during microfiltration of mosambi juice using low cost ceramic membranes, LWT - Food Science and Technology. 44 (2011) 214-223. doi:10.1016/j.Iwt.2010.06.026. 
665

666

667

668

669

670

671

672

673

674

675

676

677

678

679

680

681

682
[59] A. Giacobbo, A. Meneguzzi, A.M. Bernardes, M.N. de Pinho, Pressure-driven membrane processes for the recovery of antioxidant compounds from winery effluents, Journal of Cleaner Production. (2016). doi:10.1016/j.jclepro.2016.07.033.

[60] Y. Xue, H. Zhao, L. Ge, Z. Chen, Y. Dang, D. Sun, Comparison of the performance of waste leachate treatment in submerged and recirculated membrane bioreactors, International Biodeterioration \& Biodegradation. 102 (2015) 73-80. doi:10.1016/j.ibiod.2015.01.005.

[61] E.J. McAdam, S.J. Judd, Immersed membrane bioreactors for nitrate removal from drinking water: Cost and feasibility, Desalination. 231 (2008) 52-60. doi:10.1016/j.desal.2007.11.038.

[62] L. Qi, H. Liang, Y. Wang, G. Li, Integration of immersed membrane ultrafiltration with the reuse of PAC and alum sludge (RPAS) process for drinking water treatment, Desalination. 249 (2009) 440444. doi:10.1016/j.desal.2009.06.053.

[63] M. Ulbricht, W. Ansorge, I. Danielzik, M. König, O. Schuster, Fouling in microfiltration of wine: The influence of the membrane polymer on adsorption of polyphenols and polysaccharides, Separation and Purification Technology. 68 (2009) 335-342. doi:10.1016/j.seppur.2009.06.004.

[64] G. Belfort, R.H. Davis, A.L. Zydney, The behavior of suspensions and macromolecular solutions in crossflow microfiltration, Journal of Membrane Science. 96 (1994) 1-58. doi:10.1016/03767388(94)00119-7. 